\title{
Hypercalcaemia in osteogenesis imperfecta treated with pamidronate
}

\author{
C J C Williams, R A Smith, R J Ball, H Wilkinson
}

\begin{abstract}
The response to the bisphophosphonate, pamidronate, is reported in a child with osteogenesis imperfecta who had recurrent symptomatic hypercalcaemia after immobilisation following fractures. Oral clodronate was effective in the prevention of immobilisation hypercalcaemia in the same child. The bisphosphonates may have other roles in osteogenesis imperfecta by decreasing bone turnover. (Arch Dis Child 1997;76:169-170)
\end{abstract}

Keywords: osteogenesis imperfecta; hypercalcaemia; pamidronate; bisphophonate.

\section{Case report}

A 13 year old boy sustained a fracture of the left femur; he had fractured his right leg twice before with minimal trauma. Radiography showed gross osteopenia. His sclerae were blue. He was treated conservatively with traction.

After four weeks he developed vomiting with nausea, anorexia, constipation, polydipsia, and polyuria. Investigations showed a grossly raised serum albumin adjusted calcium of 3.54 $\mathrm{mmol} / 1$ (normal value $2.1-2.6 \mathrm{mmol} / \mathrm{l}$ ), with mildly raised urea and creatinine. Hypercalciuria was demonstrated at $21 \mathrm{mmol} / 24$ hours $(<5$ $\mathrm{mmol} / 24$ hours). Creatinine clearance was normal and parathyroid hormone (PTH) was appropriately suppressed. Other electrolytes including phosphate and alkaline phosphatase were normal. He was not on any medication and there was no history of vitamin ingestion.

Intravenous rehydration led to a fall to normal values of the urea and creatinine with little effect on the serum calcium concentration and he remained symptomatic. He was then treated with pamidronate disodium $15 \mathrm{mg}$ infused intravenously over two hours and frusemide $20 \mathrm{mg}$ orally twice daily. Informed consent was obtained from the parents and the patient as this drug is not licensed for use in children. The serum calcium concentration fell to a normal value of $2.54 \mathrm{mmol} / 1$ within three days and his symptoms improved. Over the next two weeks he was mobilised and the frusemide was discontinued. His serum calcium remained in the normal range. Repeat 24 hour urine excretion six months later showed a normal urine calcium excretion of $4.4 \mathrm{mmol} / 24$ hours. Renal ultrasound scan showed no evidence of renal calculi or nephrocalcinosis.

Two years later he again fractured his right femur and was treated with skeletal traction. After 18 days he had symptoms of hypercalcae- mia with a serum calcium of $3.27 \mathrm{mmol} / 1$. All other electrolytes were normal as was the vitamin D concentration. PTH concentrations were appropriately suppressed and hypercalciuria again demonstrated with a calcium/ creatinine ratio of $1.3 \quad(<0.6 \mathrm{mmol} / \mathrm{mmol})$ Treatment was started with intravenous fluids and frusemide $20 \mathrm{mg}$ twice a day. After two days his serum calcium remained raised at 3.24 $\mathrm{mmol} / \mathrm{l}$ so treatment with an intravenous infusion of pamidronate $15 \mathrm{mg}$ was given. Within three days his serum calcium had fallen to normal with improvement of symptoms. The frusemide was continued.

Four weeks later, while still on traction, calcium concentrations began to rise again to a peak of $3.27 \mathrm{mmol} / \mathrm{l}$ when he was again symptomatic A further dose of pamidronate $15 \mathrm{mg}$ was given with good effect.

Five weeks later during mobilisation at home he refractured his right femur. Once again he was treated conservatively in a Thomas' splint. His serum calcium, which had been normal on admission, slowly rose to $2.73 \mathrm{mmol} / 1$ after two weeks. On this occasion prophylactic treatment with oral clodronate $520 \mathrm{mg}$ twice a day was started. Serum calcium was checked weekly and found to remain in the normal range for the rest of this admission and for two weeks after discharge. He was discharged eight weeks after admission when beginning to mobilise, at which point the clodronate was stopped. No side effects were reported and the serum phosphate remained in the normal range.

\section{Discussion}

At the time of the first admission this boy had not been diagnosed as having osteogenesis imperfecta. However the presence of multiple fractures with minimal trauma, blue sclerae, radiological osteoporosis, and a family history make this diagnosis highly likely. Both his mother and his maternal aunt seem to have the same condition. He gives no history of easy bruising, abnormal scarring, hearing or dental problems. His height and weight were on the 50th centiles. There is considerable phenotypic heterogeneity in osteogenesis imperfecta but this case broadly corresponds to the Sillence type $1 \mathrm{~A} .{ }^{1}$

Hypercalciuria is a common finding in children with osteogenesis imperfecta and may correlate with disease severity, ${ }^{2}$ although its pathogenesis is not understood. Renal stones and renal papillary calcification were found in $7 \%$ of patients with osteogenesis imperfecta. ${ }^{3}$ However, increases in serum calcium are not characteristic and there is no evidence of a dis- 
turbance of calcium homoeostasis in osteogenesis imperfecta. In this patient hypercalcaemia was likely to have been caused by the effects of prolonged immobilisation, the fractures, and the osteogenesis imperfecta, which can all lead to an increase in osteoclastic activity. The responses on each occasion to the use of pamidronate and the failure of the calcium concentration to rise during prolonged treatment with clodronate in the same situation would support this hypothesis.

Both of these drugs are bisphosphonates and are potent inhibitors of osteoclastic activity through not fully understood mechanisms. In vitro they bind strongly to hydroxyapatite crystals inhibiting their formation and dissolution. In vivo the inhibition of osteoclastic activity may, at least in part, be due to the binding of the drug to bone material as these drugs are analogues of pyrophosphate. ${ }^{4}$ Potential side effects of treatment with these drugs include decreased serum phosphate concentrations, gut disturbances, pyrexia, and lymphocytopenia. None were reported in our case.

Pamidronate has been used in the treatment of osteogenesis imperfecta with a reported increase in the radiographic bone mass ${ }^{5-6}$ using an oral regimen. We would not on current evidence advocate routine use of bisphosphonates to this end. They should, however, be considered in cases of hypercalcaemia secondary to prolonged immobilisation. Prophylactic treatment with clodronate may also be considered in cases known to be at risk of developing hypercalcaemia. Where possible prolonged immobilisation should be avoided in at risk cases.

We acknowledge the help of the Orthopaedic Department, York District Hospital and of senior pharmacist Elizabeth McManus with this case.

1 Sillence DO, Senn A, Danks DM. Genetic heterogeneity in osteogenesis imperfecta. F Med Genet 1979;16:101-16.

2 Arkadi C, Petersen DJ, Schrank FW, Whyte MP. Hypercalciuria in children affected with osteogenesis imperfecta. $\mathcal{F}$ Pediatr 1991;119:51-7.

3 Vetter U, Maierhofer B, Muller M, et al. Osteogenesis mperfecta in childhood: cardiac and renal manifestations. Eur $\mathcal{F}$ Pediatr 1989;149:184-7.

4 Boonekamp PM, et al. Two modes of action of bisphophonates on osteoclastic resorption of mineralised matrix. Bone and Mineral 1986;1:27-39

5 Devogelaer JP, Malghem J, Maldague B, Nagant de Deuxchaisne C. Radiological and absorptiometric manifestations of bisphosphonate treatment with APD in a child suffering from osteogenesis imperfecta. Osteoporosis 1987; 2:953-5.

6 Huaux JP, Lokietek W. Is APD a promising drug in the treatment of severe osteogenesis imperfecta? $\mathcal{f}$ Pediatr Orthop 1988;8:71-2. 